2. Zompatori M, Poletti V, Battista G, et al. Bronchiolitis obliterans with organizing pneumonia (BOOP), presenting as a ring-shaped opacity at HRCT (the atoll sign). A case report. Radiol Med 1999;97:308-10.

3. Kim SJ, Lee KS, Ryu YH, et al. Reversed halo sign on high-resolution CT of cryptogenic organizing pneumonia: diagnostic implications. AJR Am J Roentgenol 2003:180:1251-4.

4. Marlow TJ, Krapiva PI, Schabel SI, et al. The "fairy ring": a new radiographic finding in sarcoidosis. Chest 1999;115:275-6.
5. Agarwal R, Aggarwal AN, Gupta D. Another cause of reverse halo sign: Wegener's granulomatosis. Br J Radiol 2007;80:849-50.

6. Benamore RE, Weisbrod GL, Hwang DM, et al. Reversed halo sign in lymphomatoid granulomatosis. Br J Radiol 2007;80:e162-6.

7. Gasparetto EL, Escuissato DL, Davaus T, et al. Reversed halo sign in pulmonary paracoccidioidomycosis. AJR Am J Roentgenol 2005:184:1932-4.

8. Ueda S, Inoue R, Tanaka K, et al. A case of nonspecific interstitial pneumonia with reversed halo sign on chest HRCT. Nihon Kokyuki Gakkai Zasshi 2007:45:248-52.

\title{
Notice
}

\section{Scadding-Morriston Davies joint fellowship in respiratory medicine 2011}

This fellowship is available to support visits to medical centres in the UK or abroad for the purpose of undertaking studies related to respiratory medicine. Applications are invited from medical graduates practising in the United Kingdom, including consultants and irrespective of the number of years in that grade. There is no application form but a curriculum vitae should be submitted together with a detailed account of the duration and nature of the work and the centres to be visited, confirming that these have agreed to provide the facilities required. Please state the sum of money needed for travel and subsistence. A sum of up to $£ 20000$ can be awarded to the successful candidate, or the sum may be divided to support two or more applications. Applications should be sent to the secretary by 31 January 2011.

\section{Ian Campbell}

Department of Respiratory Medicine, Academic Centre, Llandough Hospital, Cadriff, UK

Correspondence to lan Campbell, Department of Respiratory Medicine, Academic Centre, Llandough Hospital, PENARTH, Vale of Glamorgan CF64 2XX, UK; lan.campbell@wales.nhs.uk

Provenance and peer review Not commissioned; not externally peer reviewed.

Thorax 2010;65:1030. doi:10.1136/thx.2010.152249 